\title{
Editorial
}

\section{Recent Developments in Polymer/Clay Composites}

\author{
Fares D. Alsewailem*
}

Petrochemicals Research Institute, King Abdulaziz City for Science and Technology (KACST), P.O. Box 6086, Riyadh 11442, Saudi Arabia

Lately, there has been a tremendous increase in the number of publications in the field of polymer/clay composites. It is estimated that more than 700 polymer/clay research papers have been published in the last decade, i.e. from 1999 to 2008. This is approximately more than three folds of the number of publications in 1998 and before. The increased interest in polymer/clay researches in form of high number of published works during the last decade may be attributed to the advancement in methods of preparation of nanopolymer-clay composites, which exhibit marvellous properties when compared to those of the conventional polymer/clay composites. The ability of efficiently incorporating inorganic material, i.e. clay, within polymer matrices and integrating their unique individual properties into one final product has been very attractive to polymer researchers. The fact that it is possible to break clay particles into layers of high aspect ratios and disperse them within the hosted polymeric materials in form of either exfoliates or intercalates has been seen to produce high quality nano-composites with enhanced properties such as mechanical, optical, and flame-

*Address correspondence to this author at the Petrochemicals Research Institute, King Abdulaziz City for Science and Technology (KACST), P.O. Box 6086, Riyadh 11442, Saudi Arabia; Tel: +9664813522; Fax:+96614813670; E-mail: fsewailm@kacst.edu.sa retardancy properties. For example, a pellet of exfoliated polymer/clay nano-composites may appear optically clear while a conventional non-exfoliated polymer/clay pellet will be opaque. This is because the thickness of clay layers is much smaller than the wavelength of visible light. Flameretardant nano-clay polymers are being used in building in some European countries. Since last decade, people working with ordinary polymer blends and fibre-reinforced composites have been greatly influenced by the rapid progress in polymer researches. Therefore, many researchers in the area of conventional polymer blends and composites have been changing their research direction towards polymer/clay nano-composites. Immiscible polymer blends exhibit poor mechanical and physical properties. Working with clay as minor phase could easily lead to stable nano-blends. In polymer composites, e.g. glass-fibre-reinforced polymers, one realizes that there is a trade-off in some of the important properties of composite material. For example, when reinforcing thermoplastics with e-glass, the stiffness is remarkably increased but the toughness is greatly reduced. This is not the case in nano-composites where almost little or no reduction in properties is usually noticed. The aim of this issue of mini hot-topic is to present to the TOMACROJ readers the recent developments in the field of polymer/clay composites.

(C) Fares D. Alsewailem; Licensee Bentham Open.

This is an open access article licensed under the terms of the Creative Commons Attribution Non-Commercial License (http://creativecommons.org/licenses/by-nc/3.0/) which permits unrestricted, non-commercial use, distribution and reproduction in any medium, provided the work is properly cited. 